Slavica

bruxellensia

\section{Slavica bruxellensia}

Revue polyphonique de littérature, culture et histoire

slaves

9 | 2013

Érotisme

\title{
Myriam Anissimov, Vassili Grossman. Un écrivain de combat
}

\section{Laurent Béghin}

\section{OpenEdition}

\section{Journals}

Édition électronique

URL : http://journals.openedition.org/slavica/1263

DOI : 10.4000/slavica.1263

ISSN : 2034-6395

\section{Éditeur}

Université libre de Bruxelles - ULB

\section{Référence électronique}

Laurent Béghin, "Myriam Anissimov, Vassili Grossman. Un écrivain de combat », Slavica bruxellensia [En ligne], 9 | 2013, mis en ligne le 15 avril 2013, consulté le 22 septembre 2020. URL : http:// journals.openedition.org/slavica/1263; DOI : https://doi.org/10.4000/slavica.1263

Ce document a été généré automatiquement le 22 septembre 2020.

\section{(c) $(1) \&$}

Les contenus de Slavica bruxellensia sont mis à disposition selon les termes de la Licence Creative Commons Attribution - Pas d'Utilisation Commerciale - Pas de Modification 3.0 France. 


\title{
Myriam Anissimov, Vassili Grossman. Un écrivain de combat
}

\author{
Laurent Béghin
}

\section{RÉFÉRENCE}

Myriam Anissimov, Vassili Grossman. Un écrivain de combat, Paris, Seuil, 2012, 873 p. 
1 Vassili Grossman a longtemps été un communiste sincère et convaincu. Né en 1905 à Berdičev en Ukraine dans une famille de la bourgeoisie juive assimilée, l'écrivain a très tôt adhéré à la vision du monde soviétique. Ses premiers ouvrages de fiction, publiés dans les années 1930 et inspirés par son expérience d'ingénieur dans une mine du Donbass - Grossman avait étudié la chimie à l'université de Moscou - sont autant d'hymnes à l'industrialisation de l'Union soviétique et recueillent l'approbation de Maksim

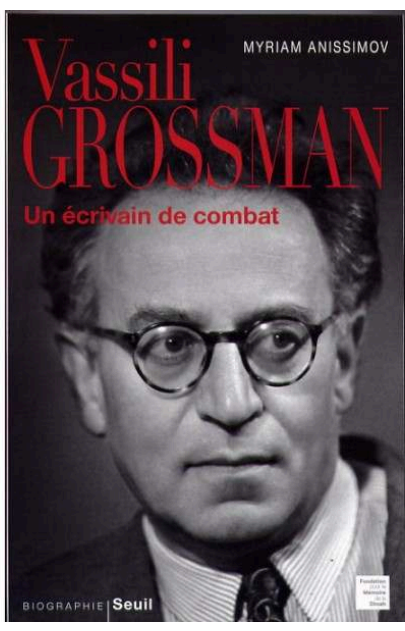
Gorkij et des coryphées du réalisme socialiste. Le jeune écrivain traverse sans encombre la période des grandes purges et jouit des avantages réservés aux auteurs officiels. Au cours de l'été 1941, après le déclenchement de l'offensive allemande, il rejoint les armées en tant que correspondant de guerre. De la défense de Moscou à la prise de Berlin, en passant par Stalingrad et Kursk, il couvrira la plupart des combats pour Krasnaja Zvezda (L'Étoile rouge), le journal des troupes. L'expérience du front lui inspire, dans les années 1950, un vaste roman intitulé Za pravoe delo (Pour une juste cause), centré sur la bataille de Stalingrad. Publié en 1952 dans Novyj Mir, le livre, s'il se distingue de nombreux ouvrages de l'époque par son refus de caricaturer les Allemands et d'héroïser excessivement le soldat russe, n'échappe pas au manichéisme qui souvent prévaut dans la littérature de guerre soviétique. Grossman y demeure un auteur officiel. Tel n'est pas le cas de Žizn' $i$ sud'ba (Vie et destin), que l'écrivain rédige juste après Za pravoe delo et qui, reprenant plusieurs personnages du premier roman, forme avec lui une dilogie. Le livre, inspiré du modèle tolstoïen - une famille de l'intelligentsia soviétique, les Šapovnikov, y joue le même rôle que les Rostov dans Guerre et paix -, établit une équation entre nazisme et stalinisme. Il contient aussi des pages douloureuses sur l'extermination des Juifs d'URSS, en particulier sur les tueries perpétrées dans le ravin de Babi Jar, non loin de Kiev, en septembre 1941, peu après la prise de la ville par les Allemands. Grossman, dont la mère a été assassinée à Berdičev par les nazis et qui, au début de l'année 1945, a écrit des reportages sur les camps de Treblinka et Majdanek, a été profondément ébranlé par la Shoah, un thème pratiquement interdit dans l'Union soviétique de l'immédiat après-guerre (pour preuve, le Livre noir sur l'extermination des Juifs soviétiques, qu'il coordonne avec ILja Èrenburg, ne pourra y être publié). Comment, dans ces conditions, Žizn' $i$ sud'ba pouvait-il obtenir l'aval des autorités ? En février 1961, des agents du KGB se présentèrent à l'appartement moscovite de Grossman et confisquèrent les différents exemplaires du roman. Heureusement l'écrivain avait caché chez des amis deux copies du livre. Après bien des tribulations, le microfilm de l'une d'elles arriva en France et fut transmis par Efim Ètkind à Vladimir Dimitrijević, le fondateur des éditions lausannoises de L’Âge d'Homme, qui le publia en 1980. Traduit en français en 1983, le roman fut salué par la critique. Pour Grossman, il était trop tard. Ébranlé par «l'arrestation » de son livre, souffrant d'un cancer des reins, l'écrivain était mort dans une clinique moscovite le 14 septembre 1964. 
2 Jusqu'à présent le lecteur de langue française disposait de trois ouvrages consacrés au romancier soviétique : Le cas Grossman, de l'universitaire Simon Markish (Julliard/L'Âge d'Homme, Paris-Lausanne, 1983), Le destin de Vassili Grossman, de l'écrivain et ami de Grossman Semën Lipkin (L'Âge d'Homme, Lausanne, 1990) et, plus récemment, La vie et le destin de Vassili Grossman, de l'écrivain et journaliste Salomon Malka (CNRS Éditions, Paris, 2008). Il s'agissait d'essais de dimensions plutôt modestes. Myriam Anissimov, qui s'est déjà penchée sur les cas de Primo Levi et de Romain Gary, a voulu donner une biographie fouillée de Grossman. Bien documenté, alimenté par des textes inédits et des témoignages de membres de la famille de l'écrivain que la biographe a recueillis au cours de son enquête, son livre suit pas à pas le romancier de 1905 à 1964. Malheureusement Anissimov ne trie pas toujours suffisamment sa documentation et assène au lecteur de nombreuses informations, parfois superflues d'ailleurs (fallait-il, par exemple, consacrer plusieurs pages aux événements qui, de 1933 à 1939, menèrent à la Seconde Guerre mondiale ?), sans que l'on saisisse toujours très bien le lien qui les unit. Un défaut que Tony Judt avait du reste déjà pointé dans son compte rendu de la biographie que Anissimov a consacrée à Levi (repris sous le titre "Les vérités élémentaires de Primo Levi» dans le recueil d'essais de l'historien anglo-américain, Retour sur le $\mathrm{XX}^{e}$ siècle. Une histoire de la pensée contemporaine, Flammarion, Paris, 2008). On déplorera enfin maintes répétitions et quelques inexactitudes qui auraient pu être aisément corrigées (ainsi à la p.221: comment l'écrivain populiste vladimir G. Korolenko aurait-il pu séjourner à Yalta en 1941 alors qu'il était mort, comme l'indique Aninissimov elle-même, en... 1921 !). C'est dommage : Grossman méritait mieux que ce livre confus.

\section{INDEX}

Mots-clés : communisme, littérature engagée

Index chronologique : communisme, Deuxième Guerre mondiale, XXe siècle

Index géographique : Russie, URSS

\section{AUTEURS}

\section{LAURENT BÉGHIN}

Institut Libre Marie Haps (Bruxelles) 